02

\title{
Колебательные спектры ионно-молекулярных кристаллов карбонатов в предпереходной области вблизи структурных фазовых переходов
}

\author{
() А.Р. Алиев, И.Р. Ахмедов, М.Г. Какагасанов, З.А. Алиев \\ Институт фозики им. Х.И. Амирханова Дагестанского НЦ РАН, \\ 367003 Махачкала, Россия \\ e-mail: amilaliev@rambler.ru
}

Поступила в редакцию 10.03.2019 г.

В окончательной редакции 10.03.2019 г.

Принята к публикации 23.04.2019 г.

Методами спектроскопии комбинационного рассеяния исследованы процессы молекулярной релаксации в карбонатах лития $\left(\mathrm{Li}_{2} \mathrm{CO}_{3}\right)$, натрия $\left(\mathrm{Na}_{2} \mathrm{CO}_{3}\right)$ и калия $\left(\mathrm{K}_{2} \mathrm{CO}_{3}\right)$. Установлено, что в кристаллических карбонатах $\mathrm{Li}_{2} \mathrm{CO}_{3}, \mathrm{Na}_{2} \mathrm{CO}_{3}$ и $\mathrm{K}_{2} \mathrm{CO}_{3}$ структурный фазовый переход первого рода носит растянутый характер. Обнаружено существование предпереходной области в исследованных карбонатах $\mathrm{Li}_{2} \mathrm{CO}_{3}, \mathrm{Na}_{2} \mathrm{CO}_{3}$ и $\mathrm{K}_{2} \mathrm{CO}_{3}$.

Ключевые слова: ионные кристаллы, комбинационное рассеяние, молекулярная спектроскопия, колебательная релаксация, предпереход, карбонаты.

DOI: $10.21883 /$ OS.2019.09.48196.104-19

\section{Введение}

Исследование конденсированных систем методами колебательной спектроскопии дает богатую информацию об их молекулярно-релаксационных и структурнодинамических свойствах [1,2], так как ширины полос в колебательном спектре обратно пропорциональны временам молекулярной релаксации [3-5]. Большое внимание в таких исследованиях уделяется структурным фазовым переходам в кристаллах, в том числе и в карбонатах [6-9]. Многие из структурных превращений являются переходами первого рода. Известно, что в области фазового перехода первого рода „кристаллрасплав“ имеют место явления предплавления [10,11]. Предпереходные явления наблюдаются в жидких кристаллах [12-15]. Исследованы предпереходные явления в металлических сплавах [16-19].

Можно предположить, что подобные предпереходные явления могут наблюдаться и при некоторых структурных фазовых переходах первого рода в кристаллах. Наряду с дифракционными методами эти явления могут с успехом изучаться и спектроскопическими методами, чувствительными к локальным взаимодействиям и нарушениям в кристаллической решетке.

В работах [20-23] исследовались структурные фазовые переходы первого рода в кристаллах $\mathrm{KPb}_{2} \mathrm{Br}_{5}$, $\left(\mathrm{NH}_{4}\right)_{2} \mathrm{WO}_{2} \mathrm{~F}_{4}, \mathrm{KPb}_{2} \mathrm{Cl}_{5},\left(\mathrm{NH}_{4}\right)_{2} \mathrm{NbOF}_{5}$. При повышении температуры разность показателей преломления сначала изменялась линейно и незначительно, а за $30-130 \mathrm{~K}$ до температуры фазового перехода наблюдается аномальное поведение двупреломления. Эта особая температурная точка на температурных зависимостях. В этих кристаллах в широком интервале температур выше фазового перехода наблюдались сильные предпереходные явления, растянутые по температуре на 30-70 K.
Теоретические представления о предпереходных состояниях развиты в работах [24-27]. В последние годы представления о предпереходных явлениях рассмотрены в [28-33].

В качестве метода исследования структурных фазовых переходов в кристаллах удобен метод колебательной спектроскопии, в том числе и метод комбинационного рассеяния (КР) света [34,35]. В отличие от других методов в колебательной спектроскопии измеряются величины, характеризующие непосредственно отдельные молекулы или ионы изучаемой системы. Этими параметрами являются положение максимума (частота $v$ ) и ширина $w$ спектральной полосы. Малейшие изменения в микроскопической структуре и строении изучаемой системы, а также в динамике молекул и ионов отражаются на спектральных параметрах $(v, w)$ этой системы.

Поэтому исследование предпереходных явлений при структурных фазовых переходах первого рода в кристаллах методом КР может способствовать установлению характера изменения механизма ионной динамики при структурном фазовом превращении. Тем более что при исследовании фазовых переходов типа „порядок-беспорядок" в нитратах щелочных металлов обнаружены предпереходные явления, изучение которых важно для понимания динамики процессов разупорядочения и ориентационного плавления в области растянутых фазовых переходов [36-38]. С точки зрения структуры рассматриваемых фаз некоторые превращения в твердом состоянии оказываются чрезвычайно важными для исследования и интерпретации процессов плавления.

В наших предыдущих работах мы исследовали область предплавления в кристаллах с многоатомными ионами методом колебательной спектроскопии [39]. При этом было установлено, что область предплавления наиболее четко проявляется в тех кристаллах, где выше сим- 
метрия молекулярного иона. В соответствие с этим в настоящей работе в качестве объектов исследования нами были выбраны карбонаты лития $\left(\mathrm{Li}_{2} \mathrm{CO}_{3}\right)$, натрия $\left(\mathrm{Na}_{2} \mathrm{CO}_{3}\right)$ и калия $\left(\mathrm{K}_{2} \mathrm{CO}_{3}\right)$. Указанные соли содержат симметричный молекулярный карбонат-ион $\mathrm{CO}_{3}^{2-}$, имеющий определенный набор нормальных колебаний с хорошо изученным спектром и активных в КР во всех фазовых состояниях. Это позволяет нам надеяться на то, что исследование колебательных спектров вблизи структурного превращения позволит обнаружить предпереходную область.

Исследование фазового перехода в карбонатах важно для понимания механизма и молекулярной природы структурных перестроек в твердых телах. В литературе мало данных, посвященных исследованиям именно этого класса ионных соединений. Поэтому исследование реориентационной подвижности и процессов разупорядочения анионов в области полиморфных превращений в карбонатах щелочных металлов методом КР является актуальной задачей.

Таким образом, в настоящей работе мы исследуем спектры КР карбонатов лития, натрия и калия в окрестности структурного фазового перехода первого рода с целью обнаружить предпереходную область.

\section{Объекты исследования}

Карбонат лития $\mathrm{Li}_{2} \mathrm{CO}_{3}$ представляет собой бесцветный кристалл с моноклинной решеткой пространственной группы $C 2 / c$, температура плавления равна $T_{m}=993-1005 \mathrm{~K}$ [40-42]. По некоторым данным [41]

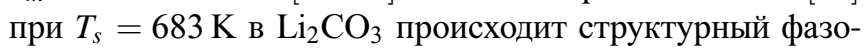
вый переход.

Карбонат натрия $\mathrm{Na}_{2} \mathrm{CO}_{3}$ представляет собой бесцветный кристалл. При температурах ниже $623 \mathrm{~K}[40,42]$ существует $\alpha$-модификация с моноклинной решеткой пространственной группы $C 2$ или $C m$. В интервале температур $632-752 \mathrm{~K}$ существует $\beta$-модификация с моноклинной кристаллической решеткой, а выше $758 \mathrm{~K}-$ гексагональная $\gamma$-модификация пространственной группы $P 6_{3} m c \quad[40,42,43]$. Температура плавления равна $T_{m}=1123-1131 \mathrm{~K}[40-43]$.

Карбонат калия $\mathrm{K}_{2} \mathrm{CO}_{3}$ - это бесцветный кристалл моноклинной сингонии пространственной группы $P 2_{1} / c$. Переход в гексагональную модификацию происходит при температуре $T_{s}=693-695 \mathrm{~K}[40,42]$. Температура плавления $T_{m}=1164-1178 \mathrm{~K}$ [40-43].

\section{Эксперимент}

Для получения информации о динамических межионных взаимодействиях нами использован анализ формы контуров колебаний молекулярных анионов в спектрах КР твердой системы. Непосредственно из фононного

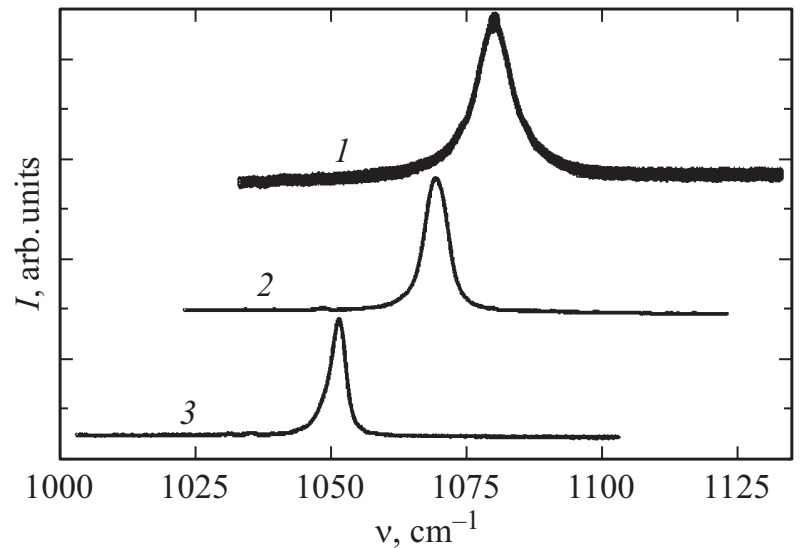

Рис. 1. Спектры КР карбонатов лития $\mathrm{Li}_{2} \mathrm{CO}_{3}$ (1), натрия $\mathrm{Na}_{2} \mathrm{CO}_{3}$ (2) и калия $\mathrm{K}_{2} \mathrm{CO}_{3}$ (3) в области валентного полносимметричного колебания $v_{1}(A)$ карбонат-иона $\mathrm{CO}_{3}^{2-}$ при температуре $T=473 \mathrm{~K}$ и ширинах входной и выходной щелей монохроматора $150(1), 100 \mu \mathrm{m}(2,3)$.

спектра получить подобную информацию не представляется возможным. Спектр малых частот высокотемпературных фаз ионных кристаллов, как правило, регистрируется в виде широкой бесструктурной полосы, обусловленной термическим смешением различных типов (трансляционных, либрационных) внешних колебаний структурных единиц.

В то же время изменения структуры и динамики твердой системы оказывает влияние на колебательные состояния ее структурных единиц и отражается в спектрах инфракрасного поглощения и КР. Поэтому использование колебательных спектров, соответствующих внутренним модам молекулярных ионов, для получения информации о процессах молекулярной релаксации в ионных кристаллах и расплавах представляется вполне обоснованным.

Спектры КР возбуждались излучением аргонового лазера ЛГ-106м-1 с длиной волны $\lambda=488 \mathrm{~nm}$ и регистрировались спектрометром ДФС-52М от 900 до $1170 \mathrm{~cm}^{-1}$ в области полносимметричного колебания $v_{1}(A)$ карбонат-иона $\left(v_{1}\left(\mathrm{CO}_{3}^{2-}\right) \approx 1040-1080 \mathrm{~cm}^{-1}\right)$ в температурном интервале $293-913 \mathrm{~K}$. Ширины входной и выходной щелей монохроматора устанавливались одинаковыми и в зависимости от интенсивности рассеяния выбирались от 100 до $150 \mu \mathrm{m}$. Положения максимумов колебательных полос фиксировались с точностью $\pm 0.5 \mathrm{~cm}^{-1}$, а их ширины с точностью $\pm 0.1 \mathrm{~cm}^{-1}$. Температура образцов поддерживалась в процессе регистрации спектров с точностью $\pm 0.5 \mathrm{~K}$. Методика регистрации и обработки спектров КР подробно описана в [44-48].

На рис. 1 показаны спектры КР твердых систем $\mathrm{Li}_{2} \mathrm{CO}_{3}, \mathrm{Na}_{2} \mathrm{CO}_{3}, \mathrm{~K}_{2} \mathrm{CO}_{3}$ в области колебания $v_{1}(A)$ аниона $\mathrm{CO}_{3}^{2-}$. Контур рассматриваемого колебания резко поляризован (изотропное рассеяние), и потому его 


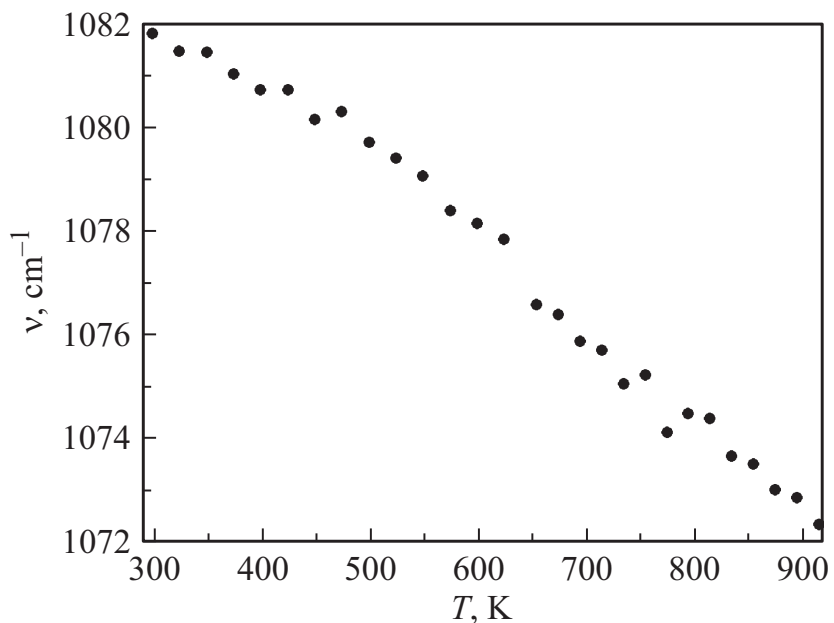

Рис. 2. Температурная зависимость $v(T)$ положения максимума спектрального контура $v_{1}(A)$ аниона $\mathrm{CO}_{3}^{2-}$ в кристаллическом карбонате лития $\mathrm{Li}_{2} \mathrm{CO}_{3}$.

формирование всецело можно приписать процессам колебательной релаксации.

На рис. 2-7 представлены температурные зависимости частот $v$ (рис. 2,4,6), ширин $w$ и интенсивностей $I$ (рис. $3,5,7)$ контура $v_{1}(A)$ колебания $\mathrm{CO}_{3}^{2-}$ в кристаллах $\mathrm{Li}_{2} \mathrm{CO}_{3}$ (рис. 2,3), $\mathrm{Na}_{2} \mathrm{CO}_{3}$ (рис. 4,5 ) и $\mathrm{K}_{2} \mathrm{CO}_{3}$ (рис. 6, 7).

Повышение температуры кристаллов от комнатной до температуры фазового перехода приводит к изменению параметров практически всех наблюдаемых в спектре полос. Общим свойством для всех спектров является смещение максимумов в низкочастотную область, уширение спектральных линий и упрощение их формы по мере повышения температуры и при переходе из низкотемпературной в высокотемпературную фазу. Вместе с тем для каждого кристалла наблюдаются свои особенности изменения спектров при температурных изменениях и фазовых превращениях. Поэтому ниже приведем обсуждение применительно к каждой соли в отдельности.

\section{Обсуждение}

На рис. 2 представлена температурная зависимость $v(T)$ положения максимума спектральной полосы, соответствующей колебанию $v_{1}(A)$ аниона $\mathrm{CO}_{3}^{2-}$ в карбонате лития $\mathrm{Li}_{2} \mathrm{CO}_{3}$. С ростом температуры частота колебания уменьшается. Примерно при $T=550 \mathrm{~K}$ имеют место определенные особенности температурной зависимости $v(T)$. При дальнейшем увеличении температуры уменьшение частоты происходит медленнее. В точке структурного фазового перехода первого рода $\left(T_{s} \approx 650 \mathrm{~K}\right)$ частота резко уменьшается. Таким образом, в интервале температур от 550 до $650 \mathrm{~K}$ имеет место предпереходная область в карбонате лития $\mathrm{Li}_{2} \mathrm{CO}_{3}$.
На рис. 3 представлены температурные зависимости $w(T)$ ширины $(I)$ и $I(T)$ интенсивности (2) спектральной полосы, соответствующей колебанию $v_{1}(A)$ аниона $\mathrm{CO}_{3}^{2-}$ в карбонате лития $\mathrm{Li}_{2} \mathrm{CO}_{3}$. С ростом температуры ширина возрастает, а интенсивность уменьшается. Примерно при $550 \mathrm{~K}$ имеют место определенные особенности температурных зависимостей $w(T)$ и $I(T)$. Интенсивность при $550 \mathrm{~K}$ резко уменьшается, a при $650 \mathrm{~K}$ это уменьшение замедляется. Ширина при $550 \mathrm{~K}$ испытывает перегиб, а при $650 \mathrm{~K}$ резко возрастает в точке структурного фазового перехода первого рода. Таким образом, в интервале температур от 550 до $650 \mathrm{~K}$ имеет место предпереходная область в карбонате лития $\mathrm{Li}_{2} \mathrm{CO}_{3}$.

На рис. 4 представлена температурная зависимость $v(T)$ положения максимума спектральной полосы, соответствующей колебанию $v_{1}(A)$ аниона $\mathrm{CO}_{3}^{2-}$ в карбонате натрия $\mathrm{Na}_{2} \mathrm{CO}_{3}$. C ростом температу-

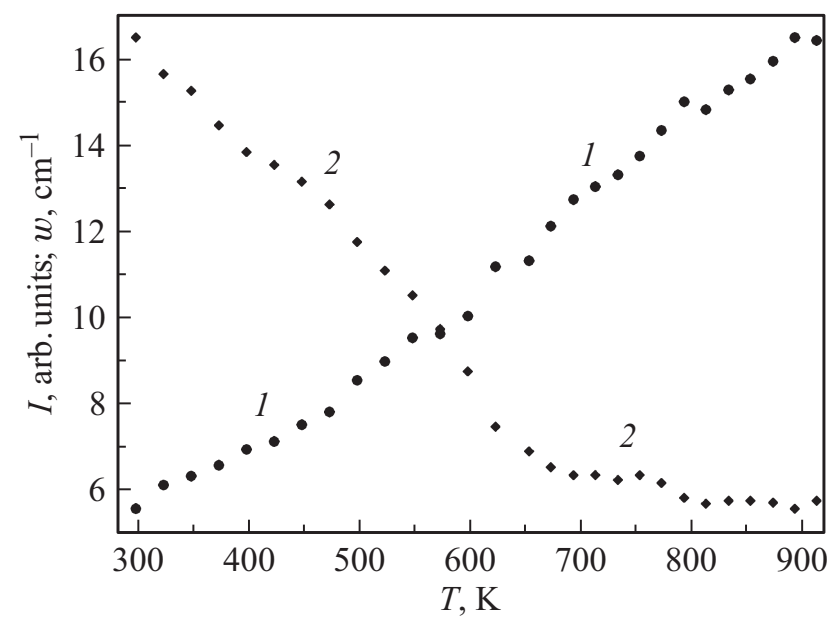

Рис. 3. Температурные зависимости ширины $w(T)(1)$ и интенсивности $I(T)(2)$ спектрального контура $v_{1}(A)$ аниона $\mathrm{CO}_{3}^{2-}$ в кристаллическом карбонате лития $\mathrm{Li}_{2} \mathrm{CO}_{3}$.

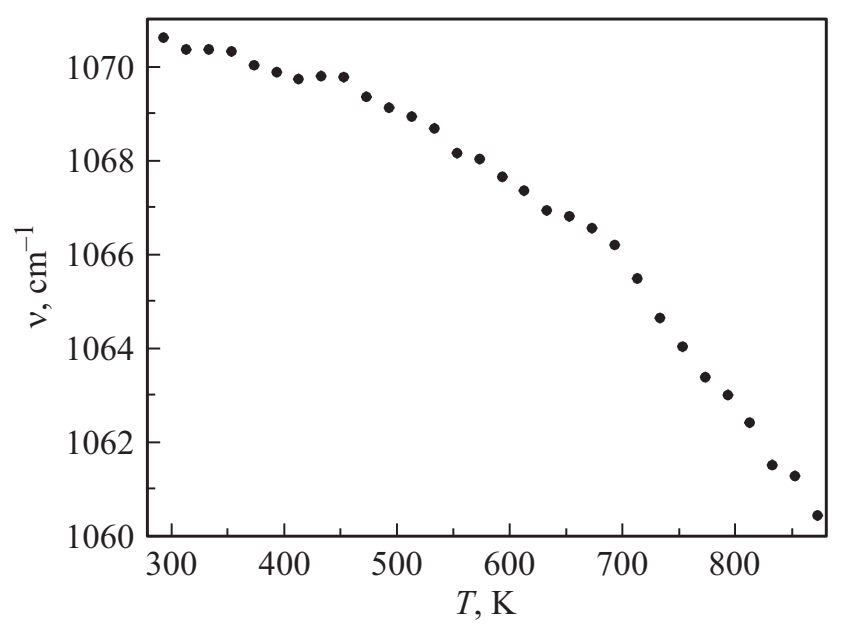

Рис. 4. Температурная зависимость $v(T)$ положения максимума спектрального контура $v_{1}(A)$ аниона $\mathrm{CO}_{3}^{2-}$ в кристаллическом карбонате натрия $\mathrm{Na}_{2} \mathrm{CO}_{3}$. 


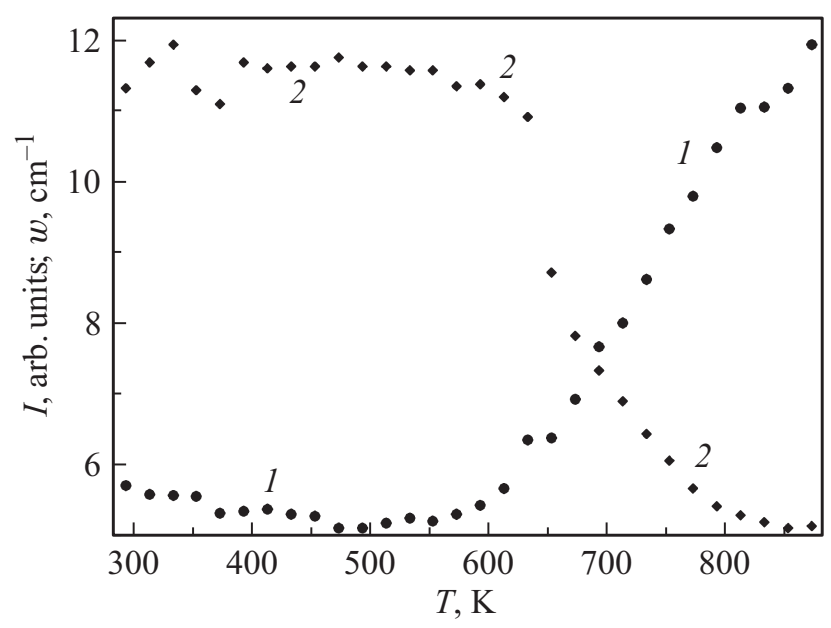

Рис. 5. Температурные зависимости ширины $w(T)(1)$ и интенсивности $I(T)(2)$ спектрального контура $v_{1}(A)$ аниона $\mathrm{CO}_{3}^{2-}$ в кристаллическом карбонате натрия $\mathrm{Na}_{2} \mathrm{CO}_{3}$.

ры частота колебания уменьшается. Примерно при $520-530 \mathrm{~K}$ имеют место определенные особенности температурной зависимости $v(T)$. При дальнейшем увеличении температуры частота продолжает уменьшаться. В точке структурного фазового перехода первого рода $\left(T_{s}=620-630 \mathrm{~K}\right)$ имеет место определенная особенность температурной зависимости $v(T)$. Таким образом, в интервале температур от 520 до $620 \mathrm{~K}$ имеет место предпереходная область в карбонате натрия $\mathrm{Na}_{2} \mathrm{CO}_{3}$.

На рис. 5 представлены температурные зависимости $w(T)$ ширины $(1)$ и $I(T)$ интенсивности (2) спектральной полосы, соответствующей колебанию $v_{1}(A)$ аниона $\mathrm{CO}_{3}^{2-}$ в карбонате натрия $\mathrm{Na}_{2} \mathrm{CO}_{3}$. C ростом температуры ширина и интенсивность практически не меняются. При температурах, больших чем 520-530 K, ширина $w(T)$ начинает возрастать, а интенсивность $I(T)$ начинает уменьшаться. Ширина резко возрастает, а интенсивность резко уменьшается в точке структурного фазового перехода первого рода $\left(T_{s}=620-630 \mathrm{~K}\right)$. Таким образом, в интервале температур от 520 до $620 \mathrm{~K}$ имеет место предпереходная область в карбонате натрия $\mathrm{Na}_{2} \mathrm{CO}_{3}$.

На рис. 6 представлена температурная зависимость $v(T)$ положения максимума спектральной полосы, соответствующей колебанию $v_{1}(A)$ аниона $\mathrm{CO}_{3}^{2-}$ в карбонате калия $\mathrm{K}_{2} \mathrm{CO}_{3}$. С ростом температуры частота колебания уменьшается. Примерно при $600 \mathrm{~K}$ имеют место определенные особенности температурной зависимости $v(T)$. При дальнейшем увеличении температуры частота практически не меняется. В точке структурного фазового перехода первого рода $\left(T_{s}=690-695 \mathrm{~K}\right)$ имеет место скачок частоты вниз. Таким образом, в интервале температур от 600 до $695 \mathrm{~K}$ имеет место предпереходная область в $\mathrm{K}_{2} \mathrm{CO}_{3}$.
На рис. 7 представлены температурные зависимости $w(T)$ ширины $(1)$ и $I(T)$ интенсивности (2) спектральной полосы, соответствующей колебанию $v_{1}(A)$ аниона $\mathrm{CO}_{3}^{2-}$ в карбонате калия $\mathrm{K}_{2} \mathrm{CO}_{3}$. С ростом температуры ширина возрастает, а интенсивность уменьшается. Примерно при $600 \mathrm{~K}$ имеют место определенные особенности температурных зависимостей $w(T)$ и $I(T)$. Уменьшение интенсивности приостанавливается при $570 \mathrm{~K}$, и в интервале температур 570-640 К интенсивность остается почти постоянной. При структурном фазовом переходе первого рода $\left(T_{s}=690-695 \mathrm{~K}\right)$ интенсивность уменьшается. Рост ширины при $T \approx 600 \mathrm{~K}$ усиливается, и в точке структурного фазового перехода первого рода $\left(T_{s}=690-695 \mathrm{~K}\right)$ имеет место скачок ширины. Таким образом, в интервале температур от 600 до $695 \mathrm{~K}$ имеет место предпереходная область в карбонате калия $\mathrm{K}_{2} \mathrm{CO}_{3}$.

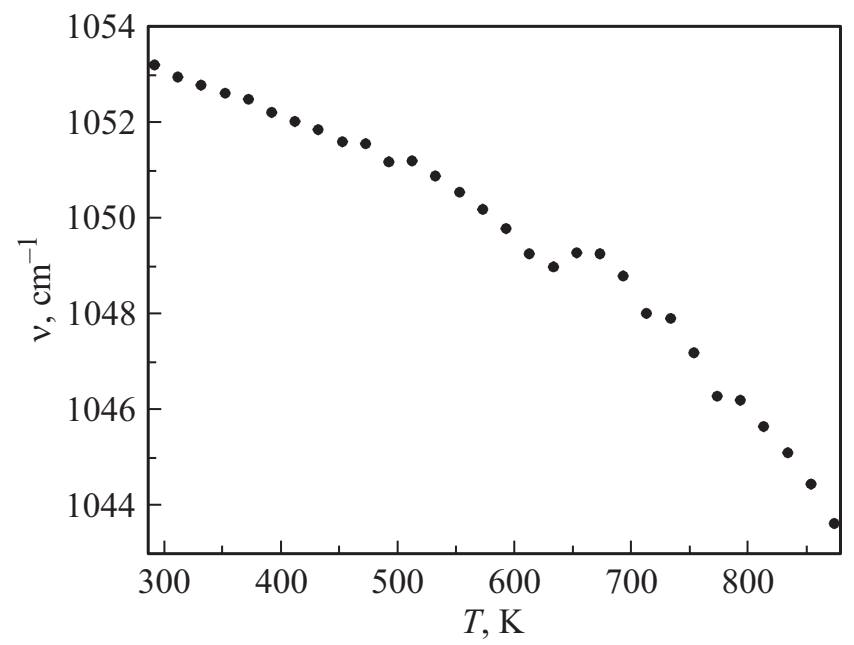

Рис. 6. Температурная зависимость $v(T)$ положения максимума спектрального контура $v_{1}(A)$ аниона $\mathrm{CO}_{3}^{2-}$ в кристаллическом карбонате калия $\mathrm{K}_{2} \mathrm{CO}_{3}$.

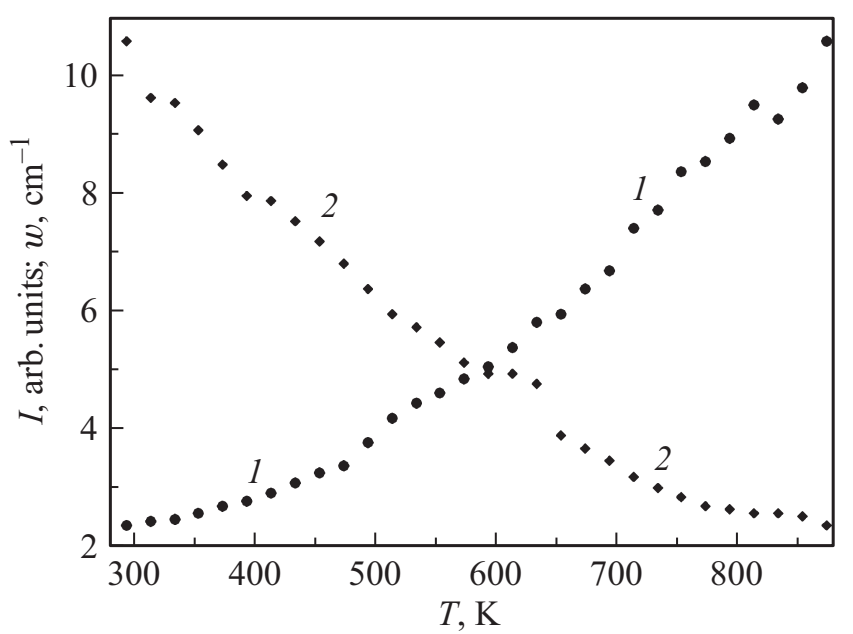

Рис. 7. Температурные зависимости ширины $w(T)(1)$ и интенсивности $I(T)(2)$ спектрального контура $v_{1}(A)$ аниона $\mathrm{CO}_{3}^{2-}$ в кристаллическом карбонате калия $\mathrm{K}_{2} \mathrm{CO}_{3}$. 


\section{Заключение}

Методами спектроскопии комбинационного рассеяния (КР) исследованы процессы молекулярной релаксации в карбонатах лития $\left(\mathrm{Li}_{2} \mathrm{CO}_{3}\right)$, натрия $\left(\mathrm{Na}_{2} \mathrm{CO}_{3}\right)$ и калия $\left(\mathrm{K}_{2} \mathrm{CO}_{3}\right)$. Обнаружено, что в кристаллических карбонатах $\mathrm{Li}_{2} \mathrm{CO}_{3}, \mathrm{Na}_{2} \mathrm{CO}_{3}$ и $\mathrm{K}_{2} \mathrm{CO}_{3}$ структурный фазовый переход первого рода носит растянутый характер. Показано существование предпереходной области в исследованных карбонатах $\mathrm{Li}_{2} \mathrm{CO}_{3}, \mathrm{Na}_{2} \mathrm{CO}_{3}$ и $\mathrm{K}_{2} \mathrm{CO}_{3}$. Установлено, что изменения структурно-динамических свойств и характера локального окружения анионов $\mathrm{CO}_{3}^{2-}$ в предпереходной области карбонатов $\mathrm{Li}_{2} \mathrm{CO}_{3}$, $\mathrm{Na}_{2} \mathrm{CO}_{3}$ и $\mathrm{K}_{2} \mathrm{CO}_{3}$ зависят от вида катиона.

\section{Список литературы}

[1] Журавлев Ю.Н., Корабельников Д.В. // Опт. и спектр. 2017. T. 122. № 6. С. 972.

[2] Горелик В.С., Аникьев А.А., Коршунов В.М., Войнов Ю.П. // ОПт. и спектр. 2017. Т. 123. № 2. С. 242.

[3] Алиев А.Р., Ахмедов И.Р., Какагасанов М.Г., Алиев З.А., Гафуров М.М., Рабаданов К.Ш., Амиров А.М. // ФТТ. 2017. T. 59. № 4. C. 736 .

[4] Алиев А.Р., Ахмедов И.Р., Какагасанов М.Г., Алиев З.А., Гафуров М.М., Рабаданов К.Ш., Амиров А.М. // Опт. и спектр. 2017. Т. 123. № 4. С. 575.

[5] Алиев А.Р., Ахмедов И.Р., Какагасанов М.Г., Алиев З.А., Гафуров М.М., Рабаданов К.Ш., Амиров А.М. // ФТТ. 2018. T. 60. № 2. C. 341.

[6] Смирнов М.Б., Hinka J. // ФТТ. 2000. Т. 42. № 12. С. 2219.

[7] Зиненко В.И., Замкова Н.Г. // ФТТ. 2001. Т. 43. № 12. C. 2193.

[8] Журавлев Ю.Н., Корабельников Д.В. // ФТТ. 2009. Т. 51. № 1. C. 65.

[9] Мурадов А.Д., Мукашев К.М., Кырыкбаева А.А. // Опт. и спектр. 2018. Т. 124. № 6. С. 748-752.

[10] Ubbelodhe A. Melting and Crystal Structure. London: Oxford Univ. Press, 1965; Уббелоде А. Плавление и кристаллическая структура. М.: Мир, 1969. С. 279.

[11] Копосов Г.Д., Бардюг Д.Ю. // Письма в ЖТФ. 2007. Т. 33. № 14. C. 80.

[12] Демихов Е.И., Долганов В.К., Филев В.М. // Письма в ЖЭТФ. 1983. Т. 37. № 7. С. 305.

[13] Анисимов М.А., Городецикий Е.Е., Поднек В.Э. // Письма в ЖЭТФ. 1983. Т. 37. № 8. С. 352.

[14] Демихов Е.И., Долганов В.К. // Письма в ЖЭТФ. 1983. T. 38. № 8. С. 368.

[15] Кизель В.А., Панин С.И. // Письма в ЖЭТФ. 1986. Т. 44. № 2. C. 74.

[16] Пушин В.Г., Кондратьев В.В., Хачин В.Н. Предпереходные явления и мартенситные превращения. Екатеринбург: УрО РАН, 1998. $367 \mathrm{c}$.

[17] Клопотов А.А., Чекалкин Т.Л., Гюнтер В.Э. // ЖТФ. 2001. T. 71. № 6. C. 130.

[18] Кузнецова Е.И. Автореф. канд. дис. Екатеринбург: Институт физики металлов УрО РАН, 2003.

[19] Гришков В.Н., Лотков А.И., Дубинин С.Ф., Теплоухов С.Г., Пархоменко В.Д. // ФТТ. 2004. Т. 46. № 8. С. 1348.
[20] Мельникова С.В., Исаенко Л.И., Пашков В.М., Певнев И.В. // ФТТ. 2005. Т. 47. № 2. С. 319.

[21] Мельникова С.В., Фокина В.Д., Лапташ Н.М. // ФТТ. 2006. T. 48. № 1. C. 110.

[22] Мельникова С.В., Исаенко Л.И., Пашков В.М., Певнев И.В. // ФТТ. 2006. Т. 48. № 11. С. 2032.

[23] Мельникова С.В., Лапташ Н.М., Александров К.С. // ФТТ. 2010. T. 52. № 10. C. 2023.

[24] Слядников E.E. // ФТТ. 2004. Т. 46. № 6. С. 1065.

[25] Слядников Е.Е. // Письма в ЖТФ. 2005. Т. 31. № 5. С. 30.

[26] Слядников E.E. // ФТТ. 2005. Т. 47. № 3. С. 469.

[27] Слядников E.E. Автореф. канд. дис. Томск: Институт физики прочности и материаловедения СО РАН, 2005.

[28] Беляев А.П., Рубеи В.П., Антипов В.В., Бордей Н.С. // ЖТФ. 2014. Т. 84. № 7. С. 156.

[29] Максимов В.И., Дубинин С.Ф., Суркова Т.П. // ФТТ. 2014. T. 56. № 12. С. 2311.

[30] Максимов В.И., Суркова Т.П., Пархоменко В.Д., Юшкова E.H. // ФТТ. 2016. Т. 58. № 4. С. 633.

[31] Беляев А.П., Рубеи В.П., Антипов В.В. // ЖТФ. 2017. Т. 87. № 4. C. 624.

[32] Алиев А.Р., Гафуров М.М., Ахмедов И.Р., Какагасанов М.Г., Алиев 3.А. // ФТТ. 2018. Т. 60. С. 1191.

[33] Максимов В.И., Максимова Е.Н., Суркова Т.П., Вохмянин А.П. // ФТТ. 2019. Т. 61. № 1. С. 42.

[34] Втюрин А.Н., Белю А., Крылов А.С., Афбанасьев М.Л., Шебанин А.П. // ФТТ. 2001. Т. 43. № 12. С. 2209.

[35] Рассеяние света вблизи точек фазовых переходов / Под ред. Камминза Г.З., Леванюка А.П. М.: Наука, 1990. 414 с.

[36] Карпов С.В., Шултин А.А. // ФТТ. 1975. Т. 17. № 10. C. 2868

[37] Аболиньш Я.Я., Карпов С.В., Шултин А.А. // ФТТ. 1978. T. 20. № 12. C. 3660 .

[38] Карпов С.В., Краевский Т., Тимофеев К.В. // ФТТ. 1995. T. 37. № 8. C. 2257.

[39] Gafurov M.M., Aliev A.R., Akhmedov I.R. // Spectrochimica Acta A. 2002. V. 58. N 12. P. 2683.

[40] Химическая энциклопедия. М.: Изд-во „Советская энциклопедия“, 1990. Т. 2. С. 288, 607; 1992. Т. 3. С. 182.

[41] Bale C.W., Pelton A.D. // CALPHAD. 1982. V. 6. N 4. P. 255.

[42] Dessureault Y., Sangster J., Pelton A.D. // J. Electrochem. Soc. 1990. V. 137. N 9. P. 2941.

[43] Lindberg D., Backman R., Chartrand P. // J. Chem. Thermodynamics. 2007. V. 39. N 6. P. 942.

[44] Aliev A.R., Gafurov M.M., Akhmedov I.R. // Mol. Phys. 2002. V. 100. N 21. P. 3385.

[45] Aliev A.R., Gafurov M.M., Akhmedov I.R. // Chem. Phys. Lett. 2002. V. 359. N 3-4. P. 262.

[46] Aliev A.R., Gafurov M.M., Akhmedov I.R. // Chem. Phys. Lett. 2002. V. 353. N 3-4. P. 270.

[47] Aliev A.R., Gadzhiev A.Z. // J. Mol. Liquids. 2003. V. 107. N 1-3. P. 59.

[48] Aliev A.R., Gafurov M.M., Akhmedov I.R. // Chem. Phys. Lett. 2003. V. 378. N 1-2. P. 155. 